\title{
Behavior and biocompatibility of rabbit bone marrow mesenchymal stem cells with bacterial cellulose membrane
}

\author{
Marcello Alencar Silva ${ }^{1}$, Yulla Klinger Leite ${ }^{1}$, Camila Ernanda Carvalho ${ }^{1}$, Matheus Tajra Feitosa ${ }^{1}$, Michel \\ Muálem Alves ${ }^{2}$, Fernando Aécio de Amorim Carvalho ${ }^{2}$, Bartolomeu Cruz Viana ${ }^{3}$, Maria Angélica Miglino ${ }^{4}$, \\ Angela Faustino Jozala ${ }^{5}$, Maria Acelina Martins Carvalho ${ }^{\text {Corresp. } 1}$ \\ 1 Integrated Nucleus of Morphology and Stem Cell Research, Federal University of Piauí, Teresina, Piauí, Brazil \\ 2 Antileishmania Activities Laboratory, Federal University of Piauí, Teresina, Piauí, Brazil \\ 3 Department of Physics / Advanced Microscopy Multiuser Laboratory / Laboratory of Physics Material, Federal University of Piauí, Teresina, Piauí, Brazil \\ 4 Departament of Surgery / Faculty of Veterinary Medicine and Animal Science, University of São Paulo, São Paulo, São Paulo, Brazil \\ 5 Laboratory of Industrial Microbiology and Fermentation Process, University of Sorocaba, Sorocaba, São Paulo, Brazil \\ Corresponding Author: Maria Acelina Martins Carvalho \\ Email address: mcelina@ufpi.edu.br
}

Background. Tissue engineering has been shown to exhibit great potential for the creation of biomaterials capable of developing into functional tissues. Cellular expansion and integration depends on the quality and surface-determinant factors of the scaffold, which are required for successful biological implants. The objective of this research was to characterize and evaluate the in vitro characteristics of rabbit bone marrow mesenchymal stem cells (BM-MSCs) associated with a bacterial cellulose membrane (BCM). We assessed the adhesion, expansion, and integration of the biomaterial as well as its ability to induce macrophage activation. Finally, we evaluated the cytotoxicity and toxicity of the BCM. Methods. Samples of rabbit bone marrow were collected. Mesenchymal stem cells were isolated from medullary aspirates to establish fibroblast colony-forming unit assay.

Osteogenic, chondrogenic, and adipogenic differentiation was performed. Integration with the BCM was assessed by scanning electron microscopy at 1, 7, and 14 days. Cytotoxicity was assessed via the production of nitric oxide, and BCM toxicity was assessed with the MTT assay; phagocytic activity was also determined. Results. The fibroblastoid colonyforming unit (CFU-F) assay showed cells with a fibroblastoid morphology organized into colonies, and distributed across the culture area surface. In the growth curve, two distinct phases, lag and log phase, were observed at 15 days. Multipotentiality of the cells was evident after induction of osteogenic, chondrogenic, and adipogenic lineages. Regarding the BM-MSCs' bioelectrical integration with the BCM, BM-MSCs were anchored in the BCM in the first $24 \mathrm{~h}$. On day 7 of culture, the cytoplasm was scattered, and on day 14 , the cells were fully integrated with the biomaterial. We also observed significant macrophage activation; analysis of the MTT assay and the concentration of nitric oxide revealed no cytotoxicity of the biomaterial. Conclusion. The BCM allowed the expansion and 
biointegration of bone marrow progenitor cells with a stable cytotoxic profile, thus presenting itself as a biomaterial with potential for tissue engineering. 
1 Behavior and Biocompatibility of rabbit bone marrow Mesenchymal Stem Cells with 2 bacterial cellulose membrane

3 Marcello A. Silva ${ }^{1}$; Yulla K. Leite ${ }^{1}$; Camila E. Carvalhoㄹ ${ }^{1}$ Matheus L. Feitosa ${ }^{1}$; Michel M. 4 Alves $^{2}$; Fernando A. Carvalho ${ }^{2}$; Bartolomeu C.Viana ${ }^{3}$; Maria Angélica Miglino ${ }^{4}$; Angela F. 5 Jozala ${ }^{5}$; Maria Acelina M. Carvalho ${ }^{1}$

6

$7{ }^{1}$ Integrated Nucleus of Morphology and Stem Cell Research, Federal University of Piauí, 8 Teresina, Piauí, Brazil.

$9{ }^{2}$ Antileishmania Activities Laboratory, Federal University of Piauí, Teresina, Piauí, Brazil.

$10{ }^{3}$ Department of Physics / Advanced Microscopy Multiuser Laboratory / Laboratory of Physics 11 Material, Federal University of Piauí, Teresina, Piauí, Brazil.

$12{ }^{4}$ Department of Surgery / Faculty of Veterinary Medicine and Animal Science, University of 13 São Paulo, São Paulo, Brazil.

${ }^{5}$ Laboratory of Industrial Microbiology and Fermentation Process, University of Sorocaba 16 UNISO, Sorocaba, São Paulo, Brazil.

Corresponding Author:

19 Maria Acelina M. Carvalho ${ }^{1}$

Email address: mcelina@ufpi.edu.br 
Background. Tissue engineering has been shown to exhibit great potential for the creation of biomaterials capable of developing into functional tissues. Cellular expansion and integration depends on the quality and surface-determinant factors of the scaffold, which are required for successful biological implants. The objective of this research was to characterize and evaluate the in vitro characteristics of rabbit bone marrow mesenchymal stem cells (BM-MSCs) associated with a bacterial cellulose membrane (BCM). We assessed the adhesion, expansion, and integration of the biomaterial as well as its ability to induce macrophage activation. Finally, we evaluated the cytotoxicity and toxicity of the BCM.

Methods. Samples of rabbits bone marrow were collected. Mesenchymal stem cells were isolated from medullary aspirates to establish fibroblast colony-forming unit assay. Osteogenic, chondrogenic, and adipogenic differentiation was performed. Integration with the BCM was assessed by scanning electron microscopy at 1, 7, and 14 days. Cytotoxicity was assessed via the production of nitric oxide, and BCM toxicity was assessed with the MTT assay; phagocytic activity was also determined.

Results. The fibroblastoid colony-forming unit (CFU-F) assay showed cells with a fibroblastoid morphology organized into colonies, and distributed across the culture area surface. In the growth curve, two distinct phases, lag and log phase, were observed at 15 days. Multipotentiality of the cells was evident after induction of osteogenic, chondrogenic, and adipogenic lineages. Regarding the BM-MSCs' bioelectrical integration with the BCM, BM-MSCs were anchored in the BCM in the first $24 \mathrm{~h}$. On day 7 of culture, the cytoplasm was scattered, and on day 14, the cells were fully integrated with the biomaterial. We also observed significant macrophage activation; analysis of the MTT assay and the concentration of nitric oxide revealed no cytotoxicity of the biomaterial.

Conclusion. The BCM allowed the expansion and biointegration of bone marrow progenitor cells with a stable cytotoxic profile, thus presenting itself as a biomaterial with potential for tissue engineering.

\section{Introduction}

Researchers have been studying bone marrow mesenchymal stem cells (BM-MSCs) for their applicability in regenerative medicine, and for improving current methodologies (Dimarino, Caplan \& Bonfield, 2013; Wei et al., 2013; Kobolak et al., 2016; Li et al., 2016). BM-MSCs are widely used in clinical and therapeutic use due to several factors: they are easily accessible; it is possible to achieve the necessary volume of cells in a short time, through culture replication; they allow autologous use or the treatment of several patients with a single sample, since the expression of HLA antigens is poor; they can be used without the need for HLA typing, making them ready for use in any patient. Even after being frozen, they preserve their characteristics, which allows the creation of bio-banks (Wabik \& Jones, 2015).

The use of mesenchymal stem cells (MSCs) has shown promise in the field of regenerative medicine. Studies have investigated the use of MSCs in cardiovascular events (Castellanos et al., 2016), immunological dysfunctions (Kaplan, Youd \& Lodie, 2011; Zao, Ren \& Han, 2016), bone 
61 repair (Emmet et al., 2016), cartilaginous and intervertebral discs (Blanquer, Grijpma \& Poot, 62 2015), tendinosis (Peach et al., 2017), and hematological malignancies (Wang, Qu \& Zhao,

63

64

2012), among others (Schnitzler et al., 2016; Squillaro, Peluso \& Galderisi, 2016). Tissue engineering is a promising multidisciplinary field that involves the development of materials or devices capable of specific interactions within biological tissues (Langer \& Vacanti, 2016). Advances in research have demonstrated biocompatibility between stem cells and biopolymers in the development of in vitro tissues capable of repairing injured areas (Lima et al., 2017; Park et al., 2017; Weinstein-Oppenheimer et al., 2017).

Several biomaterials with different physicochemical and mechanical properties have been developed, with biomedical purposes including tissue regeneration, drug delivery systems, new vascular grafts, or in vitro and in vivo tissue engineering supports (Lin, Lien \& Yeh, 2013; Yan et al., 2013; Soheilmoghaddam, Sharifzadeh \& Pour, 2014; Zulkifli, Hussain \& Rasad, 2014; Kim \& Kim, 2015; Pires, Bierhalz \& Moraes, 2015; Urbina, Algar \& García-Astrain, 2016).

The scaffold surface can generate cellular responses which can affect adhesion, proliferation, migration, biointegration, and cellular function (Abbott \& Kaplan, 2016). This interaction is especially important to define the degree of rejection of medical implants (Achatz et al., 2016).

Bacterial cellulose is an extracellular polysaccharide secreted primarily by Gluconacetobacter xylinus, an aerobic, Gram-negative, and chemoheterotrophic bacterium that can be grown in liquid medium from various sources of carbon and nitrogen, and basically uses glucose as the substrate. In culture medium, this microorganism produces very fine fibers that intertwine, forming a film with a nanofibrillar structure (Moosavi-Nasab \& Yousefi, 2011; Li et al., 2012; Panesar et al., 2012). Nanofibrils of length from 20 to $100 \mathrm{~nm}$ intertwine, forming a three-dimensional network, resulting in a high degree of hydrophilicity (Jozala et al., 2015; Rajwade et al., 2015), water retention capacity, and porosity, which allows selective permeability, adhesion of cell culture, and diffusion of the culture medium (Cavka et al., 2013; Vieira, 2013; Ashok et al., 2015; Kirdponpattara et al., 2015).

Many studies have used the bacterial cell membrane in vitro, in preclinical studies investigating drug, hormone, and protein release systems, artificial skin (Fu, Zhang \& Yang, 2013), cartilage (Cruz, Severo \& Azzolin, 2016), menisci (Achatz, Kuat \& Pfeifer, 2016), intervertebral discs (Flávaro, Arruda \& Vialle, 2016), valvular prostheses, artificial corneas, and 
92 the urethra (Rajwade, Paknikar \& Kumbhar, 2015). However, it will be necessary to improve our

93 knowledge of bacterial cellulose membrane (BCM) biointegration and biodegradation, especially

94

95

96

97

98

99

100

101

102

103

104

105

106

107

108

109

110

111

112

113

114

\section{5}

116

117

118

119

120

121

122 with respect to BM-MSCs.

This purpose of this study was to characterize and evaluate rabbit BM-MSC behavior in vitro when associated with a BCM, by analyzing adhesion, expansion, and cellular integration with the biomaterial, as well as the ability to induce macrophage activation. BCM cytotoxicity and toxicity were also evaluated.

\section{Material and Methods}

\section{Study design}

Bone marrow samples were collected from three adult rabbits and used for isolation and cryopreservation of MSC. A Mus musculus mouse was used as a source of peritoneal macrophages. To determine cellular viability, Trypan Blue staining and growth curve analysis were performed. For the fibroblastoid colony-forming unit assay, cells collected from the bone marrow (BM) cultured in 24-well plates at passage 6 were used. Chondrogenic, osteogenic, and adipogenic induction were used to assess the potential for differentiation into mesenchymal lineages. To verify BM-MSC biointegration with the BCM, inverted light microscopy and scanning electron microscopy (SEM) were used to analyze the phagocytic capacity, toxicity, and cytotoxicity of the BCM. This study was performed in strict accordance with the recommendations of the Guide for the Care and Use of Laboratory Animals of the National Institutes of Health. The protocol was approved by the Ethics Committee on the Use of Animals of the Federal University of Piauí (permit number: 268/16).

\section{Anesthetic protocol for bone marrow collection}

After solid anesthetic fasting of $4 \mathrm{~h}$, and $2 \mathrm{~h}$ of liquids, the rabbit was chemically restrained with a combination of $35 \mathrm{mg} / \mathrm{kg}$ of ketamine hydrochloride and $3 \mathrm{mg} / \mathrm{kg}$ of midazolam maleate. Trichotomy of the major trochanter region was performed, followed by antisepsis by femoral puncture with a $5 \mathrm{~mL}$ syringe; a heparinized $40 \times 12 \mathrm{~mm}$ needle was used to obtain a BM sample. For antibacterial prophylaxis, $10 \mathrm{mg} / \mathrm{kg}$ of enrofloxacin was given twice daily for 7 days, and $25 \mathrm{mg} / \mathrm{kg}$ of sodium dipyrone plus $3 \mathrm{mg} / \mathrm{kg}$ of tramadol was administered twice daily for 3 days for pain control (Ninu et al., 2017). 


\section{BM-MSC isolation, cultivation, and expansion}

125

126

127

128

129

130

131

132

133

134

135

136

137

138

139

140

141

142

143

144

145

146

147

148

149

150

151

152

153

The methodology presented was adapted from Argôlo Neto et al., 2016. Medullary aspirate $(1.5 \mathrm{~mL})$ was diluted in phosphate-buffered saline (PBS) at a ratio of $1: 1$ in $15 \mathrm{~mL}$ conical tubes. The resulting contents were filtered through $100 \mu \mathrm{m}$ mesh, deposited in a $15 \mathrm{~mL}$ conical tube containing Ficoll Histopaque at a ratio of 1:1 (Ficoll:BM), and centrifuged at 2,000 rpm for 30 min at $20^{\circ} \mathrm{C}$ to separate the cellular constituents by density gradient. The whitish halo, rich in mononuclear cells, was aspirated with an automatic pipettor (Houston), immediately diluted in sterile PBS with $1 \%$ antibiotic $(100 \mathrm{U} / \mathrm{mL}$ penicillin and $100 \mu \mathrm{g} / \mathrm{mL}$ streptomycin) for cell lavage, and re-centrifuged at $1,500 \mathrm{rpm}$ for $10 \mathrm{~min}$ at $20^{\circ} \mathrm{C}$. BM samples were resuspended in complete Dulbecco's modified Eagle's medium (DMEM) containing $3.7 \mathrm{~g} / \mathrm{L}$ sodium bicarbonate and 10-15 mM HEPES (Invitrogen, no. 15630080), $\mathrm{pH} 7.5,15 \%$ fetal bovine serum (Invitrogen), 1\% penicillin-streptomycin, 1\% L-glutamine (Invitrogen), and 1\% non-essential amino acids (Sigma), and cell viability was assessed. For this purpose, a $50 \mu \mathrm{L}$ aliquot of each sample was diluted in $50 \mu \mathrm{L} 0.2 \%$ Trypan Blue dye, and mixed in a sterilized glass vial for cell counting in a Neubauer chamber.

Cells were seeded in a six-well cell culture plate (TPP) at a density of $10^{6}$ cells/well in 2.0 $\mathrm{mL}$ of low-glucose DMEM, and kept in an incubator (Thermo Scientific Series II Water Jacket) at $37{ }^{\circ} \mathrm{C}$ in $5 \% \mathrm{CO}_{2}$ and $95 \%$ humidity. The wells were washed twice every 3 days with PBS solution containing $1 \%$ antibiotic $(100 \mathrm{U} / \mathrm{mL}$ penicillin and $100 \mu \mathrm{g} / \mathrm{mL}$ streptomycin), followed by exchange of the culture medium until the cultures reached $80 \%$ confluency. Subsequently, the wells were subjected to trypsinization with $2.0 \mathrm{~mL} 1 \times$ trypsin (Invitrogen, no. 25200-114, 10× Trypsin-EDTA solution), and incubated at $37{ }^{\circ} \mathrm{C}$ for $5 \mathrm{~min}$. Following this, trypsin was inactivated with the addition of $4.0 \mathrm{~mL}$ low-glucose DMEM. The solution was transferred to a $15 \mathrm{~mL}$ conical bottom tube, and centrifuged (FANEM refrigerated Cytocentrifuge MOD.280R Excelsa 4) at $20{ }^{\circ} \mathrm{C}$ and $1,500 \mathrm{rpm}$ for $10 \mathrm{~min}$.

The supernatant was discarded, the pellet was resuspended in $1.0 \mathrm{~mL}$ of DMEM, and a new cell count was performed. The cells in suspension were used for expansion. To do this, $10^{6}$ cells $/ \mathrm{mL}$ in $25 \mathrm{~cm}^{2}$ tissue culture bottles with $3.0 \mathrm{~mL}$ of supplemented DMEM were incubated at $37{ }^{\circ} \mathrm{C}$ in $5 \% \mathrm{CO}_{2}$ and $95 \%$ humidity. The cultures were expanded and photographed with an inverted phase-contrast microscope (COLEMAN NIB-100), and peaked with twice the original 
154 155

156

157

158

159

160

161

162

163

164

165

166

167

168

169

170

171

172

173

174

175

176

177

178

179

180

181

182

183

184

area; cell concentration was verified at each passage.

\section{Fibroblastoid colony-forming unit assay}

After plating $1 \times 10^{4}$ cells/mL of the BM-MSC rabbit fraction in 24-well plates, plates were observed daily to monitor the establishment of colonies with more than 30 cells. Cells were then fixed with 4\% paraformaldehyde for $30 \mathrm{~min}$, and stained with Giemsa for $10 \mathrm{~min}$ at room temperature. Any excess stain was washed away with distilled water. The colonies were observed and macroscopically counted on the 24-well plates. (Paramasivam et al., 2017).

\section{Cell viability}

Cell count, which determines concentration and viability, was performed using the Trypan Blue exclusion method. After mixing $30 \mu \mathrm{L}$ of the cell suspension with $30 \mu \mathrm{L}$ Trypan Blue solution (50 $\mu \mathrm{L}$ of $4.25 \%$ sodium chloride in $200 \mu \mathrm{L}$ of Trypan Blue), a $10 \mu \mathrm{L}$ aliquot was observed in a Neubauer chamber under an optical microscope (10× objective). The BM-MSC growth curve was performed in duplicate by plating $1 \times 10^{4}$ cells $/ \mathrm{mL}$ in five six-well plates, and counting two wells every $24 \mathrm{~h}$ over the course of 15 days. The culture medium of the plates was changed every 3 days to maintain nutrient availability. (Sangeetha et al., 2017).

\section{Cell differentiation}

For cell differentiation assays, we use the protocols provided by Stem Pro ${ }^{\circledR}$. Analysis of cell differentiation potential was performed with sixth-passage BM-MSCs cryopreserved in liquid nitrogen for 12 months. They were thawed and grown in $25 \mathrm{~cm}^{2}$ bottles for cell expansion until $80 \%$ confluency was reached. Cultures were then trypsinized and seeded at the concentration according to the manufacturer's instructions, for chondrogenic, osteogenic, and adipogenic differentiation.

For chondrogenic differentiation, $3 \times 10^{5}$ cells per well were seeded in a 96-well plate. After $48 \mathrm{~h}$, formation of spheroid bodies was observed, and the culture medium was replaced with that from a Stem Pro ${ }^{\circledR}$ Chondrogenesis Differentiation Kit. Exchange of the medium was performed every 3 days during a 21-day period. Analysis was performed with histological sections stained with Alcian Blue.

For osteogenic differentiation, $6 \times 10^{4}$ cells were seeded in a 24 -well plate. Initially, the 
185 supplemented culture medium was removed and replaced with the osteogenic induction medium, 186 and changed every 3 days during a 21-day period. During this period, morphological 187 characteristics of the cells were evaluated. After osteogenic differentiation, cells were stained 188 with Alizarin Red, which identifies the calcium-rich extracellular matrix, and is characteristic of 189 the presence of osteoblasts. To do this, the cell monolayer was washed with PBS, and fixed with $19010 \%$ alkaline phosphatase (AP) for $30 \mathrm{~min}$ at room temperature. The AP was then removed, the 191 cell monolayer was washed with distilled water, and Alizarin Red was added for 5 min. 192 Subsequently, the dye was removed, and five washes were performed with distilled water; the 193 calcium-rich extracellular matrix and the amount of calcium deposits were recorded with an 194 inverted light microscope.

For adipogenic differentiation, $2 \times 10^{4}$ cells per well were seeded in a 24 -well plate, and Stem Pro Adipogenesis Differentiation Kit induction medium was added once the cells reached $80 \%$ confluency. The culture medium was exchanged every 3 days over a period of 10 days. 199 Once differentiation occurred, the culture was stained with Oil Red to visualize lipid vacuoles.

\section{BM-MSC biointegration with the $\mathrm{BCM}$}

The bacterial cellulose membrane used in this study was developed in partnership with the 202 pharmacy department of Sorocaba University - UNISO (Sorocaba, São Paulo - Brazil). MCB was obtained from the culture of G. xylinus ATCC 53582 prepared using $100 \mathrm{ml}$ of the Hestrin and Schramm medium at $30^{\circ} \mathrm{C}$ for 48 hours under agitation of $150 \mathrm{rpm}$. After that, $10^{6}$ cells / mL-1 were withdrawn from the culture medium. For the production of MCB, 24 well plates were used. Each well was filled with $1 \mathrm{~mL}$ of inoculated culture medium. Plates were maintained at $30^{\circ} \mathrm{C}$ in a static culture for $0,24,48,72$ and 96 hours. MSCs were seeded onto the membrane 208 (Jozala et al., 2015).

To study BM-MSC expansion and biointegration with the BCM, $2 \times 10^{4}$ cells were cultured in 12-well plates on BCM for three distinct periods (1, 7, and 14 days). The BM-MSCs were fixed to the BCM using 3\% glutaraldehyde, washed once with PBS, and dehydrated by slow water exchange using a series of ethanol dilutions $(30 \%, 55 \%, 70 \%, 88 \%, 96 \%$, and 100\%) for $20 \mathrm{~min}$ at each concentration. For analysis by SEM (FEI Quanta FEG 250), samples were

214 fixed to the stub with double-sided carbon tape, placed in a dehumidifier for $2 \mathrm{~h}$, and metalized 215 with gold. 


\section{Phagocytic activation}

218 Phagocytic activity was assessed by collecting resident macrophages from the mouse 219 peritoneum. The animal was euthanized by cervical dislocation after being reassured and sedated 220 by intraperitoneal injection of a combination of xylazine hydrochloride and ketamine 221 hydrochloride (10 and $80 \mathrm{mg} / \mathrm{kg}$ body weight, respectively). Macrophage removal was 222 performed in a laminar flow hood with the animal affixed in the dorsal decubitus position by 223 administering $8 \mathrm{~mL}$ of sterile PBS at $4{ }^{\circ} \mathrm{C}$ into the abdominal cavity. The abdominal region was 224 softly massaged, and aspiration was performed using a needle coupled to a sterile syringe. The 225 cells were counted in a Neubauer chamber by the Trypan Blue exclusion colorimetric method, 226 and a minimum of $95 \%$ of living cells was obtained. The cells were counted using Neutral Red to 227 obtain the desired concentration of macrophages $\left(2 \times 10^{5}\right.$ cells $\left./ \mathrm{mL}\right)$. Peritoneal macrophages 228 were plated in each well, and incubated on the BCM. After $48 \mathrm{~h}$ of incubation at $37{ }^{\circ} \mathrm{C}$ and $5 \%$ $229 \mathrm{CO}_{2}, 10 \mu \mathrm{L}$ of stained zymosan solution was added, and incubation continued for $30 \mathrm{~min}$ at 37 $230{ }^{\circ} \mathrm{C}$. Following this, $100 \mu \mathrm{L}$ of Baker's fixative was added to paralyze the phagocytic process, and 231 after 30 min the plate was washed with $0.9 \%$ saline solution to remove the zymosan and Neutral

232 Red that were not phagocytized by macrophages. The supernatant was removed, $100 \mu \mathrm{L}$ of 233 extraction solution was added, and after solubilization on a Kline shaker, absorbance was 234 measured at $550 \mathrm{~nm}$ in a BioTek plate reader (model ELx800) (Souza et al., 2017).

\section{Toxicity}

237

To assess toxicity, the nitric oxide (NO) induction test was performed. Peritoneal macrophages $\left(2 \times 10^{5}\right.$ per well) were plated and incubated with the BCM after $24 \mathrm{~h}$ of incubation at $37{ }^{\circ} \mathrm{C}$ and $5 \% \mathrm{CO}_{2}$. Cell supernatants were transferred to another 96-well plate for nitrite dosing. The standard curve was prepared with sodium nitrite diluted in Milli-Q water at 1, 5, 10, $25,50,75,100$, and $150 \mu \mathrm{M}$ in the appropriate culture medium. At the different timepoints, the standard curve was determined with the same volume of Griess reagent (1\% sulfanilamide in $10 \% \mathrm{H}_{3} \mathrm{PO}_{4}[\mathrm{v}: \mathrm{v}]$ in Milli-Q water, added in equal parts to $0.1 \%$ naphthylenediamine in Milli-Q water), and the absorbance was read on a BioTek plate reader (model ELx800) at $550 \mathrm{~nm}$. Lipopolysaccharide (LPS) was used as a positive control (Sundaram et al., 2016). 


\section{BCM cytotoxicity}

The basis of cytotoxicity assays is the evaluation of biomaterial-induced interference in

250

251

252

253

254

255

256

257

258

259

260

261

262

263

264

265

266

267

268

269

270

271

272

273

274

275

276

277 cellular metabolic processes, and the investigation of processes that may intervene in cell growth/multiplication, or even culminate in cell death (Ávila et al., 2014).

According to Boersema (2016), cytotoxicity can be evaluated by different methods according to the type of cell damage: alterations in plasma membranes can be evaluated by means of dyes such as Trypan Blue and alamarBlue; alterations in the metabolic functions of mitochondria can be measured by the MTT (3-(4,5-dimethylthiazol-2-yl)-2,5-diphenyl tetrazolium bromide) colorimetric method.

The experiments were performed separately in 24-well plates. In the first plate, $2 \times 10^{5}$ macrophages per well were plated, and $500 \mu \mathrm{L}$ of supplemented RPMI 1640 medium was added. In the second plate, $1 \times 10^{5}$ BM-MSCs in low-glucose DMEM were added. The plates were incubated at $37{ }^{\circ} \mathrm{C}$ and $5 \% \mathrm{CO}_{2}$ for $4 \mathrm{~h}$ to allow for cell adhesion. Two washes were performed with their respective media for removal of nonadherent cells. Subsequently, $500 \mu \mathrm{L}$ of each medium was added, and the BCM (diameter $15.4 \mathrm{~mm}$ ) was added. Macrophages were incubated for $48 \mathrm{~h}$, and BM-MSCs for 7 days, followed by the addition of $10 \% 5 \mathrm{mg} / \mathrm{mL}$ MTT (diluted in medium). The macrophages and BM-MSCs were incubated for another $4 \mathrm{~h}$ in an incubator at 37 ${ }^{\circ} \mathrm{C}$ with $5 \% \mathrm{CO}_{2}$. The supernatant was discarded, and $100 \mu \mathrm{L}$ of dimethyl sulfoxide (DMSO) was added to all wells. The BCM was removed, and the plate was shaken for $30 \mathrm{~min}$ on a Kline shaker (model AK 0506) at room temperature for complete dissolution of the formazan. The colorimetric reading was performed in a spectrophotometer at $550 \mathrm{~nm}$ in a BioTek plate reader (model ELx800). In the control group, the same conditions were applied to the culture media and the respective cultured cells (Barud et al., 2015).

\section{Statistical analysis}

For analysis of phagocytic capacity, Student's $t$-test was used for independent samples of the cytotoxicity (MTT) and NO induction assays. GraphPad Prism version 5.0 was used to generate the graphs. These tests were performed in triplicate. 
279

280

281

282

283

284

285

286

287

288

289

290

291

292

293

294

295

296

297

298

299

300

301

302

303

304

305

306

307

308

309

310

311

312

\section{Results}

Immediately after isolation, cells from the BM appeared rounded and dispersed, and floated in the culture medium. From the first day of culture, it was possible to identify undifferentiated cells with a fibroblastoid morphology that had adhered to the plastic. On day 2, cells appeared to still be in the adhesion process (Fig. 1A). The formation and proliferation of fibroblast colonies were evident on day 5 of culture. Colonies were of varying sizes, surrounded by empty spaces, and distributed throughout the culture plate. The cells showed well-defined cytoplasmic boundaries, and nuclei with regions of condensed chromatin; the closer they were to one another, the more elongated the cells were, and they were arranged parallel to one another (Fig. 1B).

In the observation on day 10, the cells adhered and arranged in colonies with $80 \%$ confluency in a 12-well plate (Fig. 1C). After the first passage, cells reached confluency more rapidly, with only a 5-day interval until $80 \%$ confluency was reached in $25 \mathrm{~cm}^{2}$ bottles (Fig.1D,E,F).

After thawing, cell cultures exhibited viability of $96 \%$, with similar morphological characteristics and maintenance of differentiation as the primary culture. The observed time to confluency was superior to that of the first passage of the primary culture. At day 3 , the culture showed $80 \%$ confluency. In the growth curve, we identified two phases (lag and log) which corresponded to the adaptation period of the cells to the culture conditions, the exponential growth period, and the stability period with a reduction in cell growth. Data regarding cell concentration were used to evaluate cell kinetics, and are presented in Fig. $1 \mathrm{G}$.

Figure 1. CFU-F assay, bone marrow mesenchymal stem cell (BM-MSC) in culture and growth curve of stem cells. (A) cells in the adhesion process on day 2 of cell culture performed in 12-well plates (objective 20×, bar: $25 \mu \mathrm{m}$ ). (B) CFU-F assay in a 24-well plate: photomicrography of Giemsa-stained BM-MSC colonies after 5 days of cell culture at $80 \%$ confluency, and colonies with more than 30 cells per field (objective $20 \times$, bar: $25 \mu \mathrm{m}$ ), (C) cells arranged in parallel with fibroblastoid morphology at $80 \%$ confluency on day 10 of cell culture in 12-well plates (objective $10 \times$, bar: $50 \mu \mathrm{m}$ ), (D) and (E) cytoplasmic adhesion and expansion with $80 \%$ confluency in $25 \mathrm{~cm}^{2}$ bottles after trypsinization on day 15 of culture (objective $10 \times$, bar: $50 \mu \mathrm{m}$ ), (F) cells with fibroblastoid morphology arranged in parallel and in colonies at $80 \%$ confluency in $25 \mathrm{~cm}^{2}$ bottles after trypsinization on day 20 of culture $(10 \times$ objective, bar: $50 \mu \mathrm{m})$ and $(\mathrm{G})$ Growth curve of stem cells derived from rabbit bone marrow during 15 days of culture after thawing, at a concentration of $1 \times 10^{4} \mathrm{cells} / \mathrm{mL}$. Phases identified: lag (days 1-4), $\log$ (days 5-11), and culture decline (days 12-15). 
313

314

315

316

317

318

319

320

321

322

323

324

325

326

327

328

329

330

331

332

333

334

335

336

337

338

339

349

342

343

344

345

346

347

348

349

350

\section{Differentiation into BM-MSC mesodermal lineages}

The cell differentiation assay showed the potential of BM-MSCs to differentiate into chondrogenic, osteogenic and adipogenic lineages. Following chondrogenic differentiation, cells were stained vibrant blue by Alcian Blue, and control cells presented some spontaneous differentiation. During osteogenic induction, the culture demonstrated increased deposition of calcium in the extracellular matrix from day 13 of culture. On day 21 of induction, the culture exhibited osteogenic characteristics, which were confirmed with Alizarin Red staining. The negative control showed adhered cells with morphology indicative of spontaneous differentiation foci. During adipogenic differentiation, the cells gradually changed to a fibroblastoid morphology, and the cytoplasmic lipid vacuoles became bulky (Fig. 2).

Figure 2. Photomicrographs showing BM-MSC differentiation. (A) negative control for 14 days of chondrogenic differentiation (objective 10×, bar: $25 \mu \mathrm{m}$ ), (B) negative control for osteogenic differentiation for 21 days (objective $10 \times$, bar: $25 \mu \mathrm{m}$ ), (C) negative control for adipogênica differentiation for 10 days (objective 10×, bar: $25 \mu \mathrm{m}$ ), (D) BM-MSC chondrogenic differentiation (objective 20×, bar: $25 \mu \mathrm{m}$ ), (E) BM-MSC osteogenic differentiation showing calcium deposits in the extracellular matrix (objective 10×, bar: $25 \mu \mathrm{m}$ ) and (F) Photomicrograph showing the adipogenic differentiation of BM-MSCs, with lipid vacuoles present in the cytoplasm stained red with Oil Red (objective $40 \times$, bar: $25 \mu \mathrm{m}$ ).

\section{BM-MSC biointegration with the BCM}

In the BCM-associated cell culture, BM-MSCs with a fibroblastoid shape integrated with the biomaterial, and proliferation of the colonies was evident at 14 days of culture (Fig. 3 A,B).

Using SEM, it was possible to observe that the rounded shape of the cells after $24 \mathrm{~h}$ of culture was maintained after being subtly anchored to the randomly arranged fibers of the BCM. After 7 days of culture, the cells presented themselves in groups, forming colonies with several fixation points, generating greater adhesion to the biomaterial. Micrographs recorded after 14 days of cell culture show BM-MSCs with their cytoplasm fully adhered to the BCM (Fig. 3).

Figure 3. Photomicrographs of BM-MSCs adhered to the bacterial cellulose membrane (BCM) and scanning electron microscopy showing BM-MSC anchorage and biointegration with the BCM. (A) BM-MSC adhesion after 7 days of cell culture, highlighting the formation of CFU-F on the BCM (objective 20×, bar: $25 \mu \mathrm{m}$ ), (B) BM-MSC colonies after 14 days of culture (objective $10 \times$, bar: $50 \mu \mathrm{m}$ ), (C) analysis after $24 \mathrm{~h}$ of cell culture $(40,000 \times)$, (D) and (E) with after 7 (10,000x and 15,000x respectively) and (F) 14 days of culture $(40,000 \times)$.

\section{Macrophage activation and $\mathrm{BCM}$ cytotoxicity}

In the phagocytic activity assay, Student's $t$-test was performed to determine the difference between the absorbance resulting from the association of macrophages with cellulose, and the 
351 control group (macrophages in the presence of $0.2 \%$ DMSO in RPMI 1640 medium). In the

352

353

354

355

356

357

358

359

360

361

362

363

364

365

366

367

368

369

370

371

372

373

374

375

376

377

378

379

380

381

382

383

384

385

386

387

388

presence of the BCM, macrophage activity was significantly increased (Fig. 4A).

The colorimetric reading of NO release showed that the levels remained at a non-cytotoxic concentration for the cells in the presence of the BCM (Fig. 4B). The difference in NO release between the control and BCM was statistically significant at $\mathrm{p}<0.05$ (p-value $0.0184, \mathrm{t}_{0.05^{-}}$ critical: 2.6252), as was that between LPS and BCM (p-value: 0.0001; $\mathrm{t}_{0.05}$-critical: 11.1963).

The tetrazole salt (MTT), incubated with cells with full metabolic activity, showed intense mitochondrial activity (Fig. 4C,D). In this trial, the metabolism of MTT by BM-MSCs showed a statistically significant difference (p-value: $0.0001 ; \mathrm{t}_{0.05}$-critical: 2.6252 ) but there was no statistically significant difference (p-value: $0.0628 ; \mathrm{t}_{0.05}$-critical: 2,000 ) between the $\mathrm{BCM}$ associated with murine macrophages and with the control. In both conditions, cell viability was greater than $94 \%$ (Fig. 4E,F).

Figure 4. Macrophage activation and BCM cytotoxicity. (A) Zymosan particle phagocytosis by macrophages in the presence of the $\mathrm{BCM}$. The graph represents the mean \pm standard error of the mean of three independent experiments performed in triplicate (control: mean 0.28567, standard deviation 0.03161; BCM: mean 0.36100, standard deviation 0.03474). ABS: absorbance; C: control; BCM: bacterial cellulose membrane; ${ }^{*} p<0.05$. (B) Colorimetric nitrite dosage produced by macrophages treated with lipopolysaccharide (LPS) in the presence of the BCM. The plot represents the mean \pm standard error of the average of three independent experiments performed in triplicate (control: mean 100.0000, standard deviation 0.0000; LPS: mean 150.8889, standard deviation 1.0541; BCM: mean 109.6300, standard deviation 11.0047). Student's $t$-test was performed for comparison between groups and the control (0.2\% dimethyl sulfoxide [DMSO] in RPMI 1640 medium). C: control; LPS: lipopolysaccharide; BCM: bacterial cellulose membrane; ${ }^{*} p<0.05$. (C) Formazan crystals in BCM cultured with peritoneal macrophages and (D) BM-MSCs. Increasing view 40×. (E) BM-MSC viability in the BCM (control: mean 100.0000, standard deviation 0.0000; BCM: mean 94.4533, standard deviation 1.1926), and (F) viability of murine macrophages in the BCM (control: mean 100.0000, standard deviation 0.0000; BCM: mean 97.7867, standard deviation 3.3200). The plot represents the mean \pm standard error of the mean of three independent experiments performed in triplicate. Student's $t$-test was performed to compare the groups with the control (0.2\% DMSO in DMEM/RPMI medium). C: control; BCM: bacterial cellulose membrane; *p $<0.05$.

\section{Discussion}

After isolation, BM-MSCs exhibited a rounded shape in culture. During the adhesion and expansion process, their morphology modified, becoming gradually fusiform, and proliferating in parallel in colonies; the exclusion of hematopoietic cells in the medium exchanges was perceptible. Similarly, Zang et al. (2014) stated that MSCs adhere to favorable surfaces with rapid morphological changes, ranging from rounded to elongated shapes. According to Ikebe and Suzuki (2014), adhesion to plastic is the first criterion for the characterization of MSCs. In the cellular adhesion phase, physicochemical connections occur between the cells and the contact 
389

390

391

392

393

394

395

396

397

398

399

400

401

402

403

404

405

406

407

408

409

410

411

412

413

414

415

416

417

418

419

surface, including ionic forces that rapidly alter cell morphology, and which are evident after $1 \mathrm{~h}$ of culture (Bakhtina et al., 2014; Pu \& Komvopulos, 2014; Wang \& He, 2016).

The organization of cells in fibroblastoid colonies has been considered by Kisiel et al. (2012) as the second major characteristic of MSCs. In this experiment, colony formation was evident after 5 days of primary culture, suggesting that these interactions can occur without cellular differentiation, and therefore allow fibroblastoid morphology to be maintained.

Regarding cell viability after thawing, the lag phase was evident from day 1 to day 4 of the growth curve, and the log phase occurred between days 5 and 11, with exponential mitotic divisions evident mainly between days 9 and 11; a decline in the number of cell divisions occurred between days 12 and 15. Seconda et al. (2015) defined the lag phase as a relatively short stage characterized by onset of the release of cell proliferation factors. The exponential cell growth $(\log )$ phase is the second phase, in which the growth rate and duration depend on the medium used. When cellular metabolism can no longer be maintained, cells undergo apoptosis. Levels of confluence above $90 \%$ induce cell death through a mechanism of inhibition by contact, triggering apoptosis, in addition to the reduction of substrate levels of the culture medium, due to the high cellular concentration, as described by Meirelles \& Nardi (2003).

The ability to differentiate into more than one mesenchymal lineage (chondrogenic, osteogenic, or adipogenic) is an important multipotentiality feature of MSCs, and is a fundamental requirement for their characterization (Wuchter, Wagner \& Ho 2016). According to Kolf et al. (2015), the tissue formed by chondrogenic cell differentiation acquires a vibrant blue color when stained with Alcian Blue; during osteogenic differentiation, it is possible to observe the gradual deposition of calcium in the extracellular matrix, which is attributable to the presence of osteoblasts. Alizarin Red staining showed a fairly characteristic reddish coloration, providing evidence of this potential. According to Munir et al. (2017), formation of lipid vacuoles in the cell cytoplasm and staining by Oil Red characterize the formation of adipocytes; during adipogenic differentiation, several independent vacuoles can be found, and fuse as they expand inside the cell. In this study, cell culture using specific media for differentiation into mesodermal (chondrogenic, osteogenic, or adipogenic) lineages demonstrated the multipotentiality of rabbit BM-MSCs.

Cell adhesion and proliferation largely depend on the characteristics of the biomaterial surface, since interactions that occur on the surface will drive the biological responses (Chahal et 
420 al., 2016; Khayyen et al., 2016). After 7 days of culture, cells showed organization in a 421 fibroblastoid format with a tendency for cell grouping. In the analysis performed at 14 days, the

422

423

424

425

426

427

428

429

430

431

432

433

434

435

436

437

438

439

440

441

442

443

444

445

446

447

448

449

450

BM-MSCs were present in colonies, and covered the BCM surface.

Using SEM, we verified that BM cells maintain their rounded shape on the BCM surface in the first $24 \mathrm{~h}$, with few biomaterial fixation bridges. A delay in BM-MSC anchoring to the BCM was observed when compared to adhesion in culture plates, and this anchoring onset was evident in a few hours. According to Silveira et al. (2016), the three-dimensional structure of BCM nanofibers exhibits an arrangement similar to that of the collagen fibers of the extracellular matrix, and a surface with different pores can provide variable times for cell adhesion to the biomaterial.

BM-MSC anchoring and proliferation on the BCM were evident on day 7 of culture with grouped cells, and several cytoplasmic projections were evident in the BCM. On the 14th day of culture, fixation of the BM-MSCs occurred by interaction with the biomaterial. Consistent with the studies of Alberti and $\mathrm{Xu}$ (2016) and Santana et al. (2014), the presence of cytoplasmic projections and normal cell morphology are factors that confirm cytocompatibility between the BCM scaffold and cells.

Equilibrium in immune system cell activation also reflects a tissue's regenerative quality. In the presence of the BCM, the macrophages presented a statistically significant increase (pvalue $0.0002 ; \mathrm{t}_{0.05}$-critical: 4.8118 ) in their activity compared with the control group. Qiu et al. (2016) clarified that maintaining the scaffold intact during the period of adhesion and cell proliferation is important for the regenerative process and the architecture of the tissue to be repaired. The implanted biomaterial should gradually biodegrade to give rise to newly formed tissue without exacerbating an inflammatory response that compromises the repair quality. Thus, the adequate inflammatory response of the host in specific situations makes the biomaterial compatible with its use.

The ability of bacterial cellulose to be degraded has not yet been fully elucidated. In animal and human tissues, it is considered limited due to the absence of hydrolases that rupture the $\beta$ $(1,4)$ binding of the cellulose chain, which is responsible for the solubility of the biomaterial (Oliveira, Rambo \& Porto, 2013). Although the idea of a completely degradable scaffold is interesting from the point of view of tissue engineering, there remain difficulties with materials that exhibit this property, since the timing of degradation and tissue repair combined with the 
451 mechanical properties acquired by the newly formed tissue have led researchers to believe that a 452 material with a low rate of degradation may respond better when the scarring process requires 453 more time-consuming conditions (Bhattacharjee et al., 2015).

454 After inflammation, macrophages release NO as a way to eliminate pathogens. In addition, $455 \mathrm{NO}$ is known as an inflammatory response mediator, inhibiting or inducing inflammation 456 according to the concentration of NO released (Taraballi et al., 2016). The colorimetric nitrite 457 dosage produced by macrophages in the presence of the BCM showed a non-cytotoxic 458 concentration, approaching the value obtained in the control group.

459 The MTT assay is a method to assess cell viability widely used to evaluate the metabolism 460 of MTT in the mitochondria of viable cells when incubated with cells with full metabolic activity 461 crossing the plasma membrane, and which, when coming in contact with the superoxide 462 produced by mitochondrial activity, is reduced by succinate dehydrogenase present in MTT463 formazan-containing mitochondria. The crystals formed are insoluble in water; however, they are 464 solubilized in DMSO medium, and show violet coloration. Thus, cell viability is directly 465 proportional to the intensity of staining (Toh, Yap \& Lim, 2015). According to Li, Zhou, and Xu 466 (2015), a material is considered non-cytotoxic and biocompatible when cell viability is greater 467 than $70 \%$. In this study, the MTT assay presented intense violet staining, showing that the BCM 468 469 does not produce a toxic effect on the cells; 94\% cellular viability is considerably favorable for non-interference of cellular activity.

\section{Conclusion}

The expansion and cellular integration of biomaterials depends greatly on the quality and suitability of the biomaterial surface. The BCM allowed the adhesion, expansion, and biointegration of BM-MSCs, and the cytotoxicity and toxicity of the BCM were low enough to maintain considerable viability in cell culture. Macrophage activation and the rate of BCM degradation make the BCM an ideal biomaterial for slow healing processes in which reconstructed tissues require a scaffold with longer durability.

Considering the interaction demonstrated between BM-MSCs and the BCM, it can be stated that the $\mathrm{BCM}$ is a promising biomaterial in tissue engineering and regenerative medicine. However, it will be necessary to test the behavior of BCM implants in vivo. 
483

484 Acknowledgments

485 The Integrated Nucleus of Morphology and Stem Cell Research (NUPCelt), 486 Interdisciplinary Laboratory of Advanced Materials (LIMAV), Advanced Microscopy Multiuser 487 Laboratory (LMMA) and Antileishmania Activity Laboratoy (LAA) from the Federal University 488 of Piauí - UFPI as well as the Laboratory of Toxicological Research - LAPETOX and 489 Laboratory of Industrial Microbiology and Fermentation Process - LAMINFE, both are UNISO. 490

491 
492

493

494

495

496

497

498

499

500

501

502

503

504

505

506

507

508

509

510

511

512

513

514

515

516

517

518

519

520

521

522

523

524

525

526

527

\section{REFERENCES}

Abbott R, Kaplan D. 2016. Engineering Biomaterials for Enhanced Tissue Regeneration, Current Stem Cell Reports, 22(2):140-146. DOI: 10.1007/s40778-016-0039-3.

Achatz F, Kujat R, Pfeifer C, Koch M, Nerlich M, Angele P, Zellner J. 2016. In Vitro Testing of Scaffolds for Mesenchymal Stem Cell-Based Meniscus Tissue Engineering-Introducing a New Biocompatibility Scoring System, Materials, 9(4):1-14 DOI: 10.3390/ma9040276.

Agatha H. Kisiel DVM, Laurie A, Mcduffee DVM, Masaoud E, Bailey TR, Gonzalez BPE, FongNino R. 2012. Isolation, characterization, and in vitro proliferation of canine mesenchymal stem cells derived from bone marrow, adipose tissue, muscle, and periosteum, American Journal of Veterinary, 73(8):1305-1317 DOI 10.2460/ajvr.73.8.1305.

Argôlo Neto NM, Feitosa MLT, Sousa SS, Fernandes PB, Pessoa GT, Bezerra DO, Almeida HM, Carvalho YKP, Rocha AR, Silva LMC, Carvalho MAM. 2016. Isolation, Expansion, Differentiation and Growth Kinetics Essay in Mesenchymal Stem Cells Culture from the Bone Marrow of Collared Peccaries (Tayassu tajacu). Acta Scientiae Veterinariae, 44(1341): 1-11.

Alberti KA, Xu Q. 2016. Biocompatibility and degradation of tendon-derived scaffolds, Regenerative biomaterials, 1(1):1-11 DOI 10.1093/rb/rbv023.

Bakhtina A, Tohfafarosh M, Lichtler A, Arinzeh TL. 2014. Characterization and differentiation potencial of rabbit mesenchymal stem cells for translational regenerative medicine. In Vitro Cellular \& Developmental Biology - Animal. 50: 251. DOI 10.1007/s11626-013-9702-5.

Barud HGO, Barud HS, Cacicchioli M, Amaral TS, Oliveira Junior OB, Santos DM, Petersen ALOA, Celes F, Borges VM, Oliveira CI, Oliveira PF, Furtado RA, Tavares DC, Ribeiro SJL. 2015. Preparation and characterization of a bacterial cellulose/silk fibroinsponge scaffold for tissue regeneration. Carbohydrate Polymers. 128: 41-51 DOI 10.1016/j.carbpol.2015.04.007.

Bhattacharjee M, Coburn J, Centolo M, Murab S, Barbero A, Kaplan DL, Martin I, Ghosh S. 2015. Tissue engineering strategies to study cartilage development degeneration and regeneration. Advanced Drug Delivery Reviews. 85:107-122.

Blanquer SBG, Grijpma DW, Poot AA. 2015. Delivery systems for the treatment of degenerative intervertebral discs. Advanced Drug Reviews. 84:172-187 DOI 10.1016/j.addr.2014.10.024.

Castellanos AM, Balkan W, DiFede DL, Hare JM. 2016. Cell infection site influences the human mesenchymal stem cell therapy effectiveness for left ventricular dysfunction in ischemic cardiomyopathy. Circulation. 123(1):A192102 DOI 10.1161/ CIRCULATIONAHA.116.024610.

Chahal S, Hussain FSJ, Kumar A, Rasad MSBA, Yusoff MM. 2016. Fabrication, characterization and in vitro biocompatibility of electrospun hydroxyethyl cellulose/poly (vinyl) alcohol nanofibrouscomposite biomaterial for bone tissue engineering, Chemical Engineering Science, 144(22):17-29 DOI 10.1016/j.ces.2015.12.030. 
528 Cruz IBM, SEVERO AL, Azzolin VF, Garcia LFM, Kuhn A, Lech O. 2016. Potencial regenerativo

529 do tecido cartilaginoso por células-tronco mesenquimais: atualização, limitações e desafios. Revista 530 Brasileira de Ortopedia. 1-9 DOI 10.1016/j.rbo.2016.02.007.

531 DiMarino AM, Caplan AI \& Bonfield TL. 2013. Mesenchymal stem cells in tissue repair. Frontier in 532 Immunology, 4:1-9 DOI 10.3389/fimmu.2013.00201.

533 Emmet TM, Amos M, Daniel KJ, John GP, O’Brien FJ. 2016. An Endochondral Ossification-Based 534 Approach to Bone Repair: Chondrogenically Primed Mesenchymal Stem Cell-Laden Scaffolds Support 535 Greater Repair of Critical-Sized Cranial Defects Than Osteogenically Stimulated Constructs In Vivo.

536 Tissue Engieering Part A. 22(5-6): 556-567 DOI 10.1089/ten.tea.2015.0457.

537 Fávaro RC, Arruda AO, Vialle LR, Vialle EN. 2016. Influência da terapia celular mononuclear sobre a 538 degeneração discal em coelhos. Revista Brasileira de Ortopedia. 1(9). DOI 10.1016/j.rbo.2016.03.007.

539 Fu L, Zhang J, Yang G. 2013. Present status and applications of bacterial cellulose-based materials for 540 skin tissue repair. Carbohydrate Polymers. 92:1431-1442.

541 Ikebe C, Suzuki K. 2014. Mesenchymal Stem Cells for Regenerative Therapy: optimization of Cell 542 Preparation Protocols, Biomed Research International. 1(1):1-11 DOI 10.1155/2014/951512.

Jozala AF, Pértile RAN, Santos CA, Santos-Ebinuma VC, Seckler MM, Gama FM, Pessoa Junior A. 2015. Bacterial cellulose production by Gluconacetobacter xylinus by employing alternative culture media. Applied Microbiology and Biotechnology. 99(3): 1181-1190 DOI 10.1007/s00253-014-6232-3.

546 Kaplan JM, Youd ME, Lodie TA. 2011. Immunomodulatory activity of mesenchymal stem cells. Current Stem Cell Research \& Therapy. 6(4):297-316 DOI 10.2174/157488811797904353.

Kobolak J, Dinnyes A, Memic A, Khademhosseini A, Mobasheri A. 2016. Mesenchymal stem cells: Identification, phenotypic characterization, biological properties and potential for regenerative medicine through biomaterial micro-engineering of their niche. Methods. 99: 62-68. DOI 551 10.1016/j.ymeth.2015.09.016.

552 Khayyeri H, Longo G, Gustafsson A, Isaksson H. 2016. Comparison of structural anisotropic soft 553 tissue models for simulating Achilles tendon tensile behavior. Journal of the mechanical behavior of 554 biomedical materials, 6(1):431-443 DOI/10.1016/j.jmbbm.2016.04.007.

Kim M, Kim G. 2015. 3D multi-layered fibrous cellulose structure using an electrohydrodynamic 557 process for tissue engineering. Journal of Colloid and Interface Science. 457:180-187. DOI 10.1016/j.jcis.2015.07.007.

Kolf CM, Song L, Helm J, Tuan RS. 2015. "Nascent osteoblast matrix inhibits osteogenesis of human 559 mesenchymal stem cells in vitro". Stem Cell research \& Therapy, 22(6):1-16 DOI 10.1186/s13287-015560 0223-x.

561 Langer R, Vacanti J. 2016. Advanced in tissue engineering, Journal of Pediatric Surgery, 1(51):8-12 562 DOI 10.1016/j.jpedsurg. 2015.10.022. 
563 Li W, Zhou J, Xu Y. 2015. Study of the in vitro cytotoxicity testing of medical devices (Review). 564 Biomedical Reports. 3: 617-620 DOI 10.3892/br.2015.481.

565 Li X, Yuan Z, Wei X, LI H, Zhao G, Miao J, Wu D, Liu B, Cao S, An D, Ma W, Zhang H, Wang W, 566 Wang Q, Gu H. 2016. Application potencial of bone marrow mesenchymal stem cell (BMSCs) based 567 tissue-engineering for spinal cord defect repair in rat fetuses with spina bifida aperta, Tissue engineering 568 constructs and cell substrates, 27(4): 1-11 DOI 10.1007/s10856-016-5684-7.

569 Lima FMT, Pinto FCM, Costa BLSA, Silva JGM, Campos Júnior O, Aguiar JLA. 2017. 570 Biocompatible bacterial cellulose membrane in dural defect repair of rat. Journal of Materials Science: 571 Materials in Medicine. 28-37. DOI 10.1007/s10856-016-5828-9.

572 Lin WC, Lien CC, Yeh HJ, Yu CM, Hsu SH. 2013. Bacterial cellulose and bacterial cellulose-chitosan 573 membranes for wound dressing applications. Carbohydrate Polymers. 94: 603-611 DOI 574 10.1016/j.carbpol.2013.01.076.

575 Meirelles LS, Nardi NB. 2003. Murine marrow-derived mesenchymal stem cell: isolation, in vitro 576 expansion, and characterization. British Journal of Hematology. 123(4). DOI 10.1046/j.1365577 2141.2003.04669.x.

578 Munir H, Ward LSC, Sheriff L, Kemble S, Nayar S, Barone F, Nash GB, McGettrick HM. 2017. 579 Adipogenic differentiation of mesenquimal stem cells afters their immunomodulatory properties in a 580 tissue-specifc manner. Stem Cells. DOI 10.1002/stem.2622.

581 Ninu AR, Maiti SK, Kumar SM, Kumar S, Sangeetha P, Kritaniya D, Gupta S, Saxena A, Kumar 582 N. 2017. Isolation, proliferation, characterization and in vivo osteogenic potential of bone-marrow 583 derived mesenchymal stem cells (rBMSC) in rabbit model. Indian Journal of Experimental Biology.

584 Oliveira VA, Rambo CR, Porto LM. 2013. Produção e degradação in vitro de estruturas tubulares de 585 celulose bacteriana. Polimeros. DOI 10.4322/polimeros.2013.041.

586

587

588

589

590

591

592

593

594

595

596
Paramasivam T, Maiti SK, Palakara S, Rashmi, Singh P, Kumar N, Manjunthaachar, Plank C. 2016. Culture, Characterization and Differentiation Potential of Rat Bone Marrow derived Mesenchymal Stem Cells. Journal of Stem Cell Research \& Therapeutics. 1(5): 1-9. DOI 10.15406/jsrt.2016.01.00034.

Park S-B, Lih E, Park K-S, Joung YK, Han DK. 2017. Biopolymer-based functional composites for medical applications. Progress in Polymer Science. 77-105. DOI 10.1016/j.progpolymsci.2016.12.003.

Peach MS, Ramos DM, James R, Morozowich NL, Mazzocca AD, Doty SB, Allcock HR, Kumbar SG, Laurencin CT. 2017. Engineered stem cell niche matrices for rotador cuff tendo regenerative engineering. Plos One. 1-19. DOI 10.1371/journal.pone.0174789.

Pires A, Bierhalz A, Moraes A. 2015. Biomateriais: tipos, aplicações e mercado, Química nova, 38(7): 957-971 DOI 10.5935/0100-4042.20150094. 
597

598

599

600

601

602

603

604

605

606

607

608

609

610

611

612

613

614

615

616

617

618

619

620

621

622

623

624

625

626

627

628

629

630

631

632

PU J, Komvopoulos K. 2014. Mechanical properties of electrospun bilayer fibrous membranes as potential scaffolds for tissue engineering, Acta Biomaterialia, 10(1):2718-2726. DOI 10.1016/j.actbio.2013.12.060.

Qiu Y, Qiu L, Cui J, Wei Q. 2016. Bacterial cellulose and bacterial cellulose-vaccarin membranes for wound healing. Materials Science and Engineering C. 59:303-309.

Rajwade JM, Paknikar KM, Kumbhar JV. 2015. Applications of bacterial cellulose and itd composites in biomedicine. Appl Microbiol Biotechnol. 99:2491-2511. DOI 10.1007/s00253-015-6426-3.

Sangeetha P, Maiti SK, Divya Mohan, Shivaraju S, Raguvaran R, Malik AR, Bindhuja BV, Naveen K, Raguvanshi PDS. 2017. Mesenchymal Stem Cells Derived from rat boné marrow (rBM MSC): Techniques for isolation, expansion and differentiation. Journal of Stem Cell Research \& Therapeutics. 3(3): 1-8 DOI: 10.15406/jsrt.2017.03.00101.

Santana CC, Nóbrega Neto PI, Sá MJC. 2014. Utilização do filme de quitosana na reparação de tendão em coelhos. Arquivo brasileiro de medicina veterinária e zootecnia, 66(4):995-1002 DOI 10.1590/16786521.

Schnitzler AC, Verma A, Kehoe DE, Jing D, Murrell JR, Der KA, Aysola M, Rapiejko PJ, Punreddy S, Rook MS. 2016. Bioprocessing of human mesenchymal stem/stromal cells for therapeutic use: Current technologies and challenges. Biochemical Engineering Journal. 108:3-13.

Secunda R, Vennila R, Mohanashankar AM, Rajasundari S, Surendran R. 2015. Isolation, expansion and characterisation of mesenchymal stem cells from human bone marrow, adipose tissue, umbilical cord blood and matrix: a comparative study, Cytotechnology, 67(5):793-807 DOI: 10.1007/s10616-014-9718-z.

Silveira RK, Coelho ARB, Pinto FCM, Albuquerque AV, Filho DAM, Aguiar, JLA. 2016. Bioprosthetic mesh of bacterial cellulose. Materials in Medicine, 27(8):1-9 DOI: 10.1007/s10856-0165744-z.

Soheilmoghaddam M, Sharifzadeh G, Pour RH, Wahit MU, Whye WT, Lee XY. 2014. Regenerated cellulose/ $\beta$-cyclodextrin scaffold prepared using ionic liquid. Material Letters. 135: 210-2013 DOI: 10.1016/j.matlet.2014.07.169.

Souza AC, Alves MMM, Brito LM, Oliveira LGC, Sobrinho-Júnior EPC, Costa ICG, Freitas SDL, Rodrigues KAF, Chaves MH, Arcanjo DDR, Carvalho AA. 2017. Platonia insignis Mart., a Brazilian Amazonian Plant: The Stem Barks Extract and Its Main Constituent Lupol Expert Antileishimanial Effects Involving Macrophages Activation. Evidence-Based Complementary and Alternative Medicine. 2017: 1-12 DOI: 10.1155/2017/3126458

Squillaro T, Peluso G, Galderisi. 2016. Clinical trials with mesenchymal stem cells: an update. Cell Transplatation, 25:829-848 DOI:10.3727/096368915X689622.

Sundaram J, Pant J, Goudie MJ, Mani S, Handa H. 2016. Antimicrobial and Physicochemical Characterization of Biodegradable, Nitric Oxide-Releasing Nanocellulose-Chitosan Packaging 
633 Membranes. Journal of Agricultural and Food Chemistry. 64(25): 5260-5266 DOI: 634 10.1021/acs.jafc.6b01936.

635 Taraballi F, Corradetti B, Minardi S, Powel S, Cabrera F, Van Eps JL, Weiner BK, Tasciotti E. 636 2016. Biomimetic collagenous scaffold to tune inflammation by targeting macrophages. Journal of Tissue 637 Engeneering. 7:1-13 DOI: 10.1177/204173141524667.

638 Toh WS, Yap AUJ, Lim SY. 2015. In vitro biocompatibility of contemporary bulk-fill composites. 639 Operative Dentistry. 40(6):644-652. DOI 10.2341/15-059-L.

640 Urbina L, Algar I, García-Astrain C, Gabilondo N, González A, Corcuera MA, Eceiza A, Retegi A. 641 2016. Journal of Applied Polymer. 1-10 DOI: 10.1002/APP.43669.

642 Wang S, Qu X, Zhao R.C. 2012. Clinical applications of mesenchymal stem cells. Journal of 643 Hematology \& Oncology, 19(5):1-9.

644 Wang W, He J, Feng B, Zhang Z, Zhou G, Cao Y, Fu W, Liu W. 2016. Aligned nanofibers direct 645 human dermal fibroblasts to tenogenic phenotype in vitro and enhance tendon regeneration in vivo, 646 Nanomedicine, 11(9):1055-1072 DOI: 10.2217/nnm.16.24.

647 Wei X, Yang X, Han Z, Qu F, Shao L, Shi Y. 2013. Mesenchymal stem cells: a new trend for cell 648 therapy, Acta Pharmacologica Sinica, 34(6):747-754 DOI: 10.1038/aps.2013.50.

649 Weinstein-Oppenheimer CR, Brown DI, Coloma R, Morales P, Reyna-Jeldes M, Diaz MJ, Sánchez 650 E, Acevedo CA. 2017. Design of a hybrid biomaterial for tissue engineering: Biopolymer-scaffold 651 integrated with an autologous hydrogel carrying mesenchymal stem-cells. Materials Science and 652 Engineering: C. 79; 821-830 DOI 10.1016/j.msec.2017.05.116.

653 Wuchter P, wagner W, Ho A.D. 2016. Mesenchymal Stromal Cells (MSC). IN: Regenerative Medicine 654 - From protocol to Paciente. 3 ed. Switzerland: Springer.

655 Xi J, Yan X, Zhou J, Yue W, Pei X. 2013. Mesenchymal stem cells in tissue repairing and regeneration: 656 Progress and future. Burns \& Trauma, 1(1):13-20.

657 Zhang W, Hang F, Shi H, Tan R, Ye G, Pan S, Sun F, Liu X. 2014. Comparisons of Rabbit bone 658 marrow mesenchymal stem cell isolation and culture methods in vitro. Plos One, 9:1-8 DOI: 659 10.1371/journal.pone.0088794.

660 Zhao Q, Ren H, Han Z. 2016. Mesenchymal stem cells: Immunomodulatory capability and clinical 661 potencial in imune diseases. Journal of Cellular Immunotherapy, 2:3-20 DOI: 662 10.1016/j.jocit.2014.12.001.

663 Zulkifli FH, Hussain FSJ, Rasad MSA, Yusoff MM. 2014. Nanostructure materials from hydroxyethyl 664 cellulose for skin tissue engineering. Carbohydrate Polymers. 144:238-245 DOI: 665 10.1016/j.carbpol.2014.08.019. 


\section{Figure 1}

CFU-F assay, bone marrow mesenchymal stem cell (BM-MSC) in culture and growth curve of stem cells.

(A) cells in the adhesion process on day 2 of cell culture performed in 12-well plates (objective 20x, bar: $25 \mu \mathrm{m}$ ). (B) CFU-F assay in a 24-well plate: photomicrography of Giemsastained BM-MSC colonies after 5 days of cell culture at $80 \%$ confluency, and colonies with more than 30 cells per field (objective 20x, bar: $25 \mu \mathrm{m}$ ), (C) cells arranged in parallel with fibroblastoid morphology at $80 \%$ confluency on day 10 of cell culture in 12-well plates (objective 10x, bar: $50 \mu \mathrm{m}$ ), (D) and (E) cytoplasmic adhesion and expansion with $80 \%$ confluency in $25 \mathrm{~cm}^{2}$ bottles after trypsinization on day 15 of culture (objective 10x, bar: 50 $\mu \mathrm{m}),(\mathrm{F})$ cells with fibroblastoid morphology arranged in parallel and in colonies at $80 \%$ confluency in $25 \mathrm{~cm}^{2}$ bottles after trypsinization on day 20 of culture (10x objective, bar: 50 $\mu \mathrm{m})$ and $(\mathrm{G})$ Growth curve of stem cells derived from rabbit bone marrow during 15 days of culture after thawing, at a concentration of $1 \times 10^{4}$ cells $/ \mathrm{mL}$. Phases identified: lag (days 1-4), $\log$ (days 5-11), and culture decline (days 12-15). 

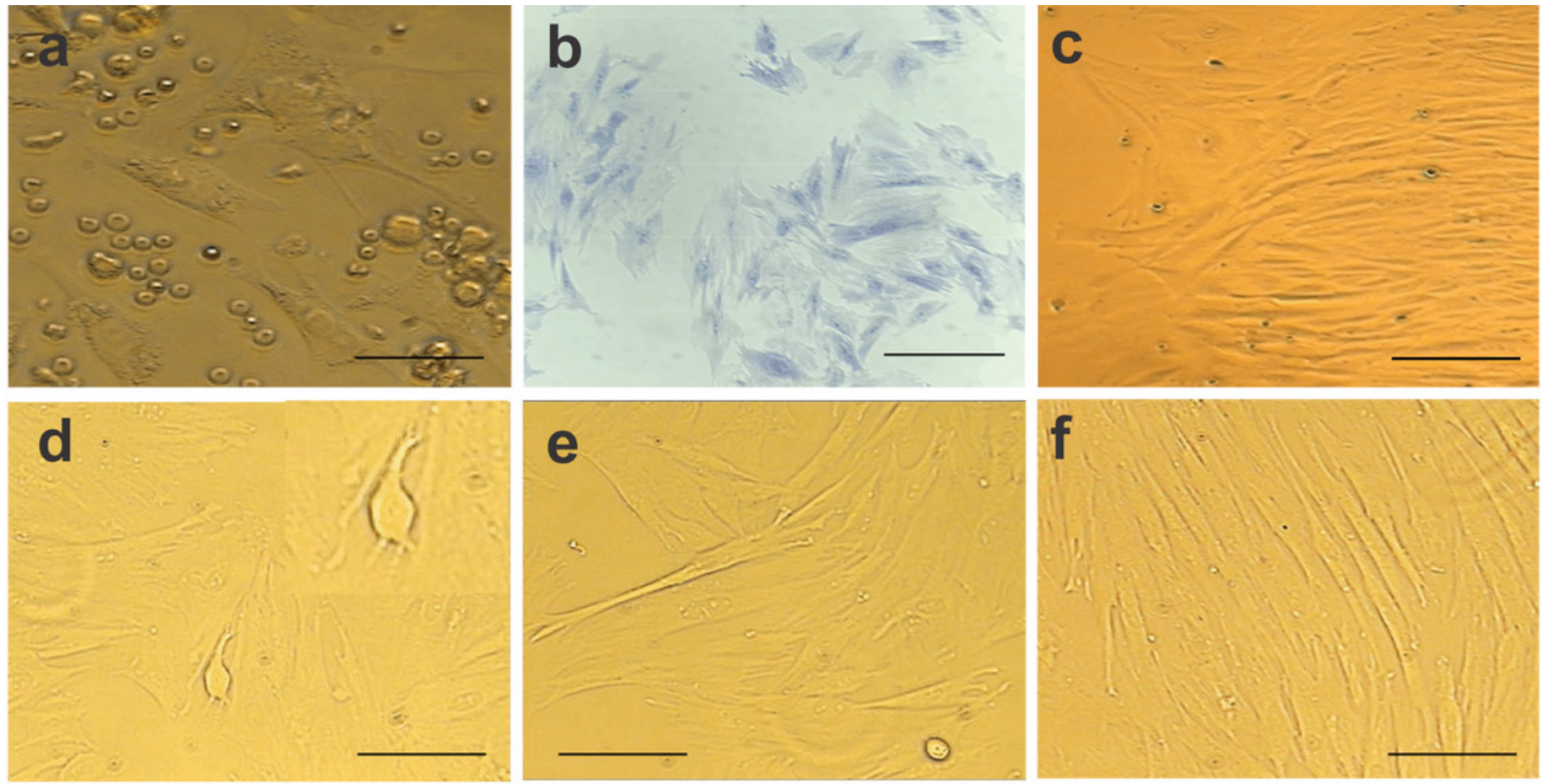

g

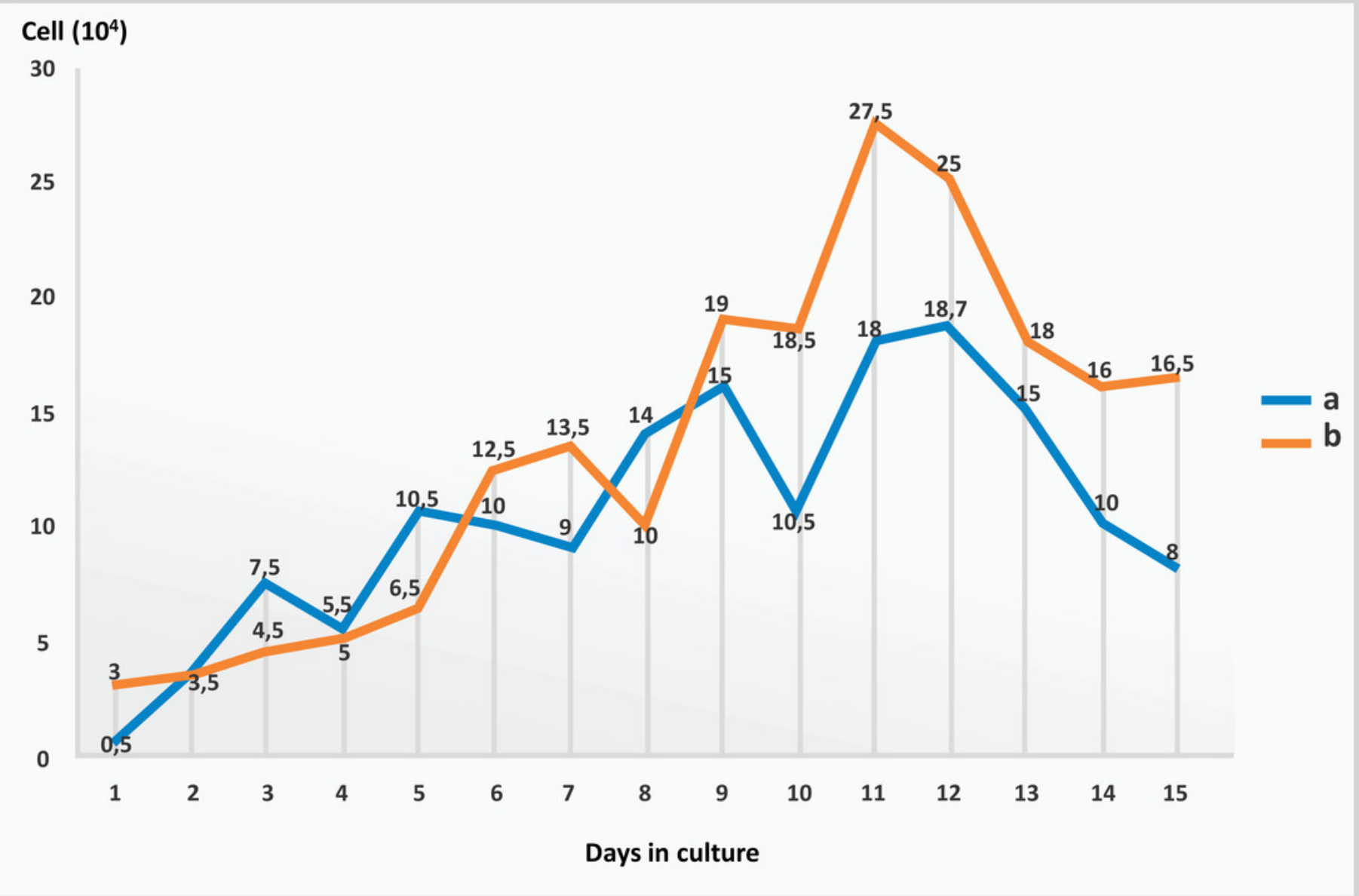




\section{Figure 2}

Photomicrographs showing BM-MSC differentiation.

(A) negative control for 14 days of chondrogenic differentiation (objective 10x, bar: $25 \mu \mathrm{m}$ ),

(B) negative control for osteogenic differentiation for 21 days (objective 10x, bar: $25 \mu \mathrm{m}$ ), (C)

negative control for adipogênica differentiation for 10 days (objective 10x, bar: $25 \mu \mathrm{m}$ ), (D) BM-MSC chondrogenic differentiation (objective 20x, bar: $25 \mu \mathrm{m}$ ), (E) BM-MSC osteogenic differentiation showing calcium deposits in the extracellular matrix (objective 10x, bar: 25 $\mu \mathrm{m})$ and (F) Photomicrograph showing the adipogenic differentiation of BM-MSCs, with lipid vacuoles present in the cytoplasm stained red with Oil Red (objective 40x, bar: $25 \mu \mathrm{m}$ ).
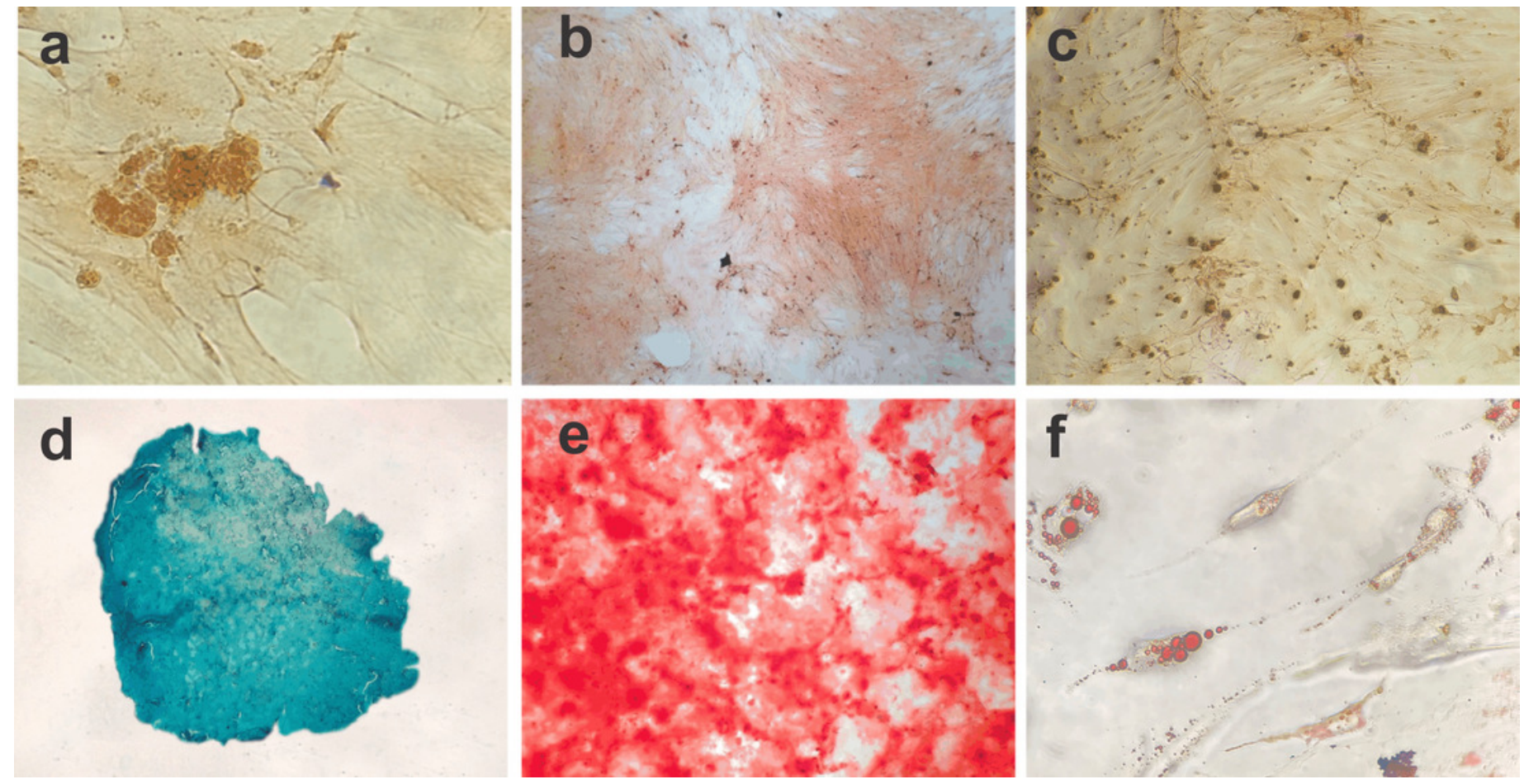


\section{Figure 3}

Photomicrographs of BM-MSCs adhered to the bacterial cellulose membrane (BCM) and scanning electron microscopy showing BM-MSC anchorage and biointegration with the BCM.

(A) BM-MSC adhesion after 7 days of cell culture, highlighting the formation of CFU-F on the BCM (objective 20x, bar: $25 \mu \mathrm{m}$ ), (B) BM-MSC colonies after 14 days of culture (objective $10 \times$, bar: $50 \mu \mathrm{m}),(C)$ analysis after $24 \mathrm{~h}$ of cell culture $(40,000 \times),(D)$ and $(E)$ with after 7 $(10,000 x$ and $15,000 x$ respectively) and (F) 14 days of culture $(40,000 x)$. 


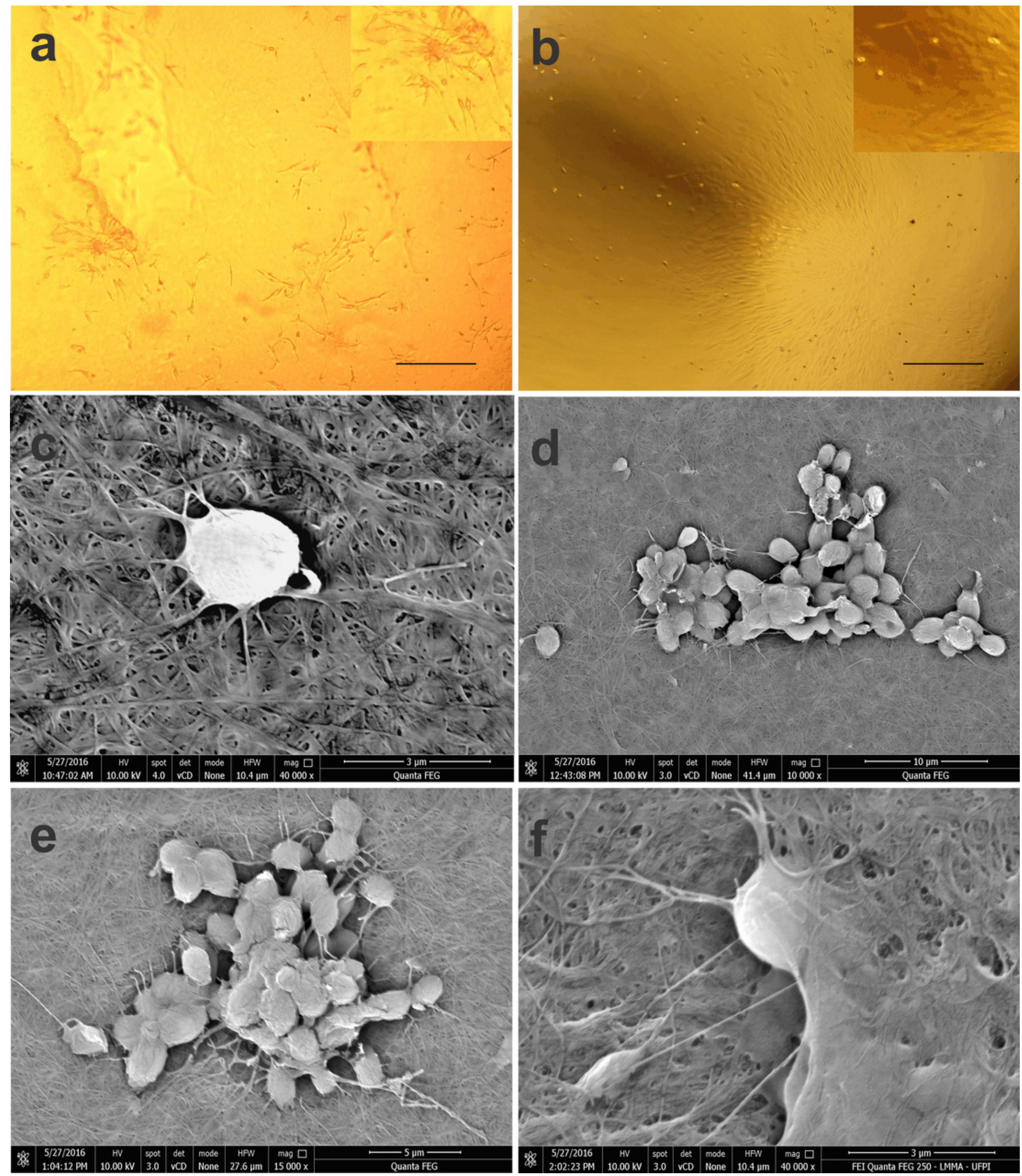




\section{Figure 4}

Macrophage activation and BCM cytotoxicity.

(A) Zymosan particle phagocytosis by macrophages in the presence of the BCM. The graph represents the mean \pm standard error of the mean of three independent experiments performed in triplicate (control: mean 0.28567, standard deviation 0.03161; BCM: mean 0.36100, standard deviation 0.03474). ABS: absorbance; C: control; BCM: bacterial cellulose membrane; $* p<0.05$. (B) Colorimetric nitrite dosage produced by macrophages treated with lipopolysaccharide (LPS) in the presence of the BCM. The plot represents the mean \pm standard error of the average of three independent experiments performed in triplicate (control: mean 100.0000, standard deviation 0.0000; LPS: mean 150.8889, standard deviation 1.0541; BCM: mean 109.6300, standard deviation 11.0047). Student's $t$-test was performed for comparison between groups and the control ( $0.2 \%$ dimethyl sulfoxide [DMSO] in RPMI 1640 medium). C: control; LPS: lipopolysaccharide; BCM: bacterial cellulose membrane; ${ }^{*} p<0.05$. (C) Formazan crystals in BCM cultured with peritoneal macrophages and (D) BM-MSCs. Increasing view 40x. (E) BM-MSC viability in the BCM (control: mean 100.0000, standard deviation 0.0000; BCM: mean 94.4533, standard deviation 1.1926), and (F) viability of murine macrophages in the BCM (control: mean 100.0000, standard deviation 0.0000; BCM: mean 97.7867, standard deviation 3.3200). The plot represents the mean \pm standard error of the mean of three independent experiments performed in triplicate. Student's $t$-test was performed to compare the groups with the control $(0.2 \%$ DMSO in DMEM/RPMI medium). C: control; BCM: bacterial cellulose membrane; ${ }^{*} p<0.05$. 
a

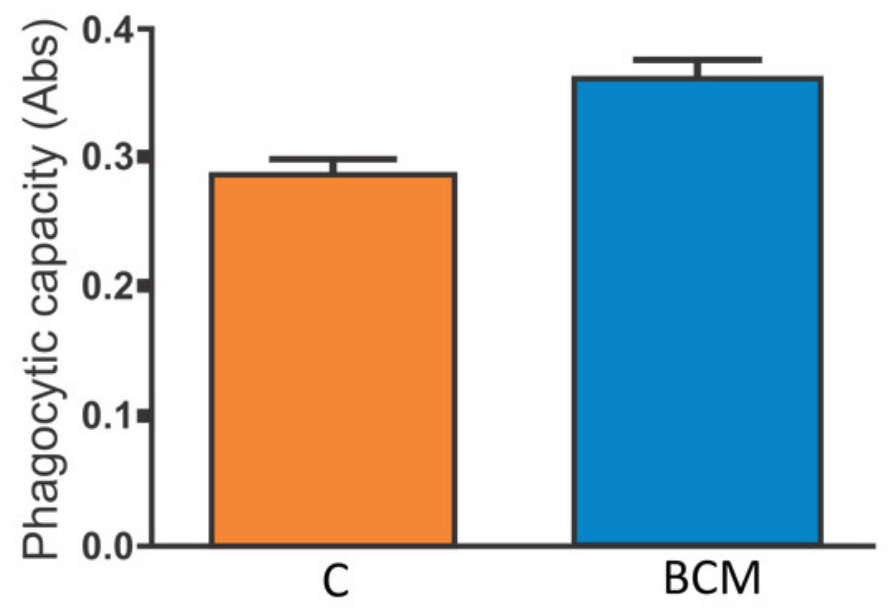

C

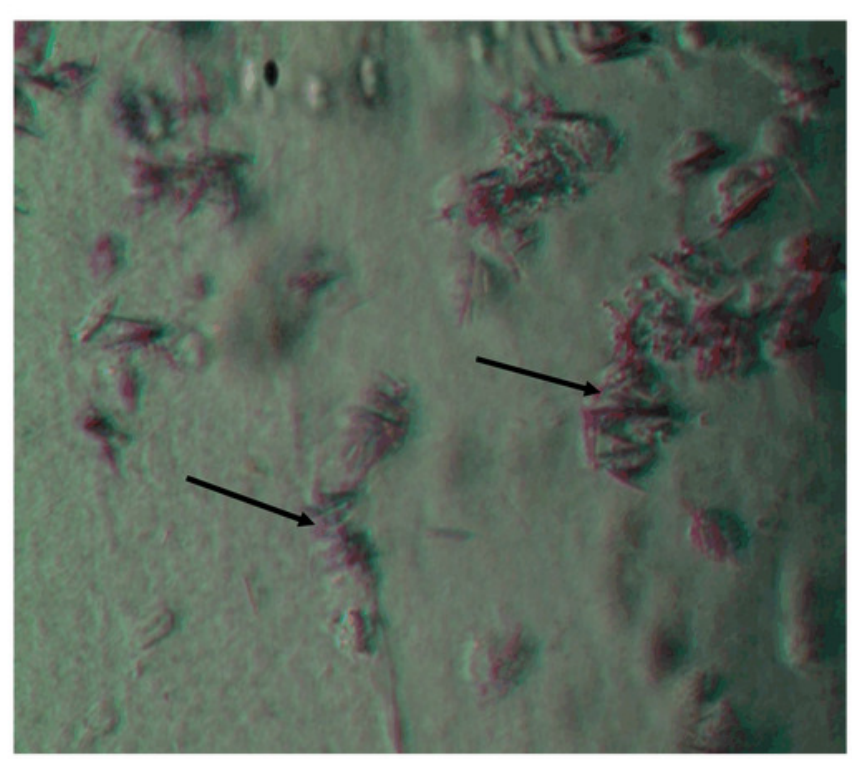

e

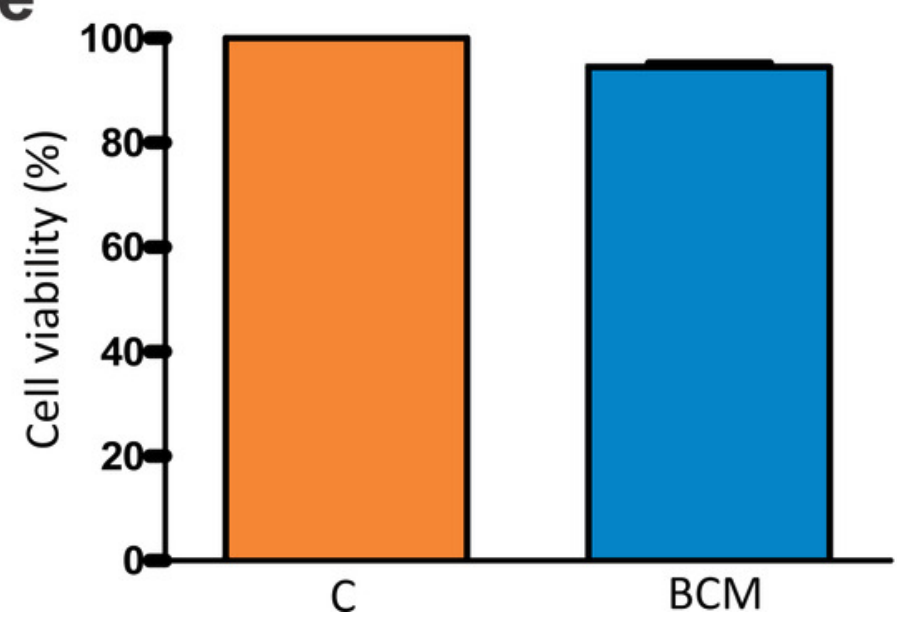

b

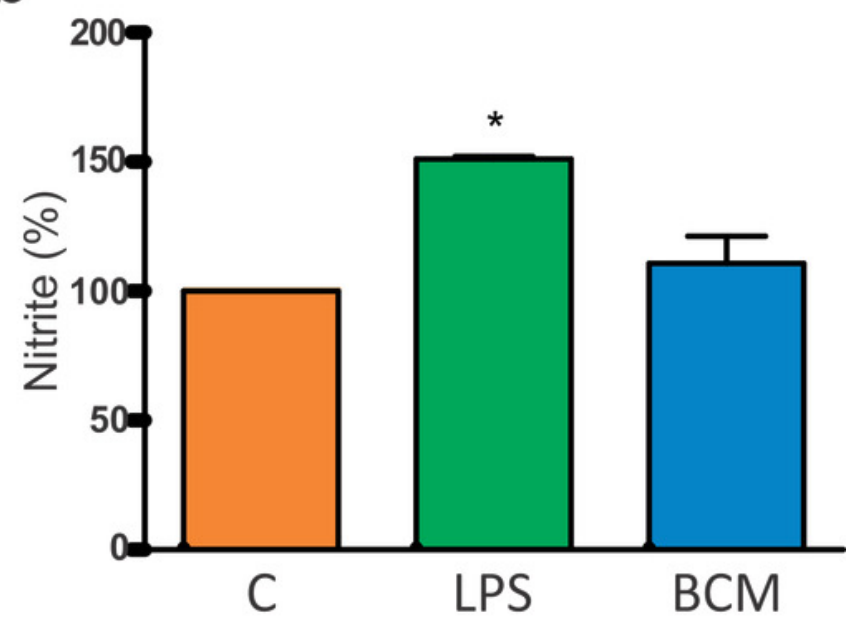

d

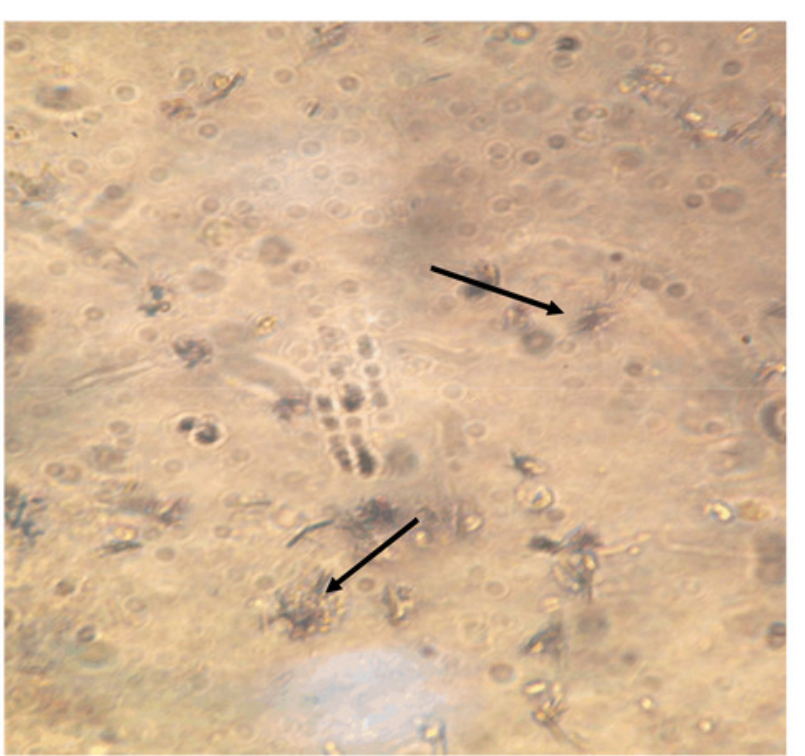

f

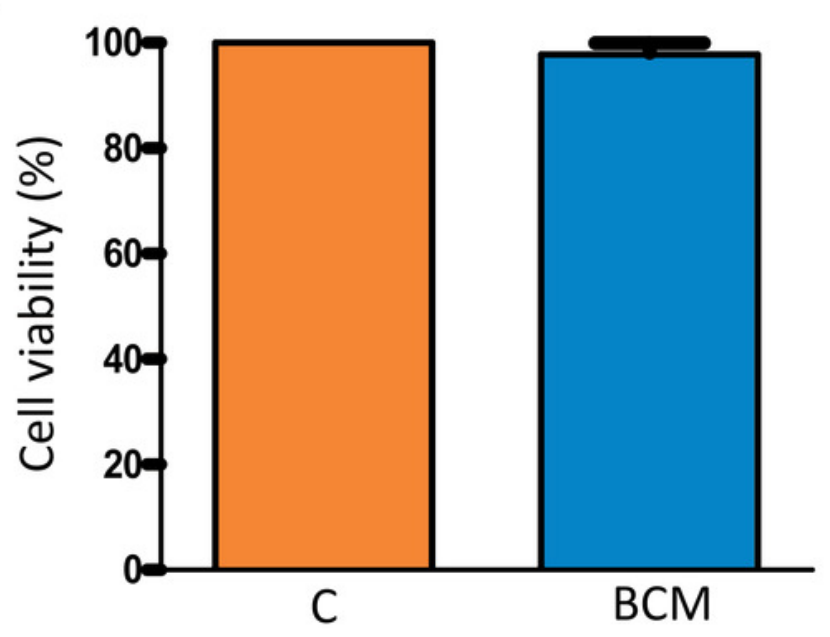

